\title{
LISTERIA MONOCYTOGENES: A PROPÓSITO DE UN BROTE
}

Durante el año 2008 dos países distantes entre sí geográficamente y en nivel de desarrollo, han debido enfrentar una situación epidemiológica similar, que ha puesto a prueba a las autoridades de salud, a los médicos clínicos de distintas especialidades, la interacción entre ellos, y a la respuesta de la población frente al problema.

Canadá y Chile han vivido un brote de listeriosis, infección causada por Listeria monocytogenes $(1,2)$. Se trata de un cuadro que habitualmente produce un síndrome febril con malestar general y diarrea, autolimitado. Sin embargo, en cierta población, especialmente embarazadas, recién nacidos e inmunosuprimidos pueden tener consecuencias graves, como meningitis, sepsis, aborto y mortalidad perinatal.

Los gineco-obstetras hemos tenido que enfrentar cada cierto tiempo la gravedad de esta enfermedad, pero no estábamos habituados a que se presentase en un brote. Por ello, cuando nos reunimos inicialmente a discutir el tema en las instancias científicas correspondientes, hubo voces que calificaron de "exageración" y de "sobre reacción", el llamado a la educación estricta a las embarazadas en relación a su alimentación, y a sugerirles que se privasen de ingerir ciertos alimentos durante la gestación. Sin considerar, que además de la realidad del brote que se estaba viviendo, existen otras infecciones que se transmiten por alimentos y que pueden afectar gravemente a la madre y al niño en gestación. Toxoplasmosis, por ejemplo, también se puede prevenir en forma importante si enseñamos a la embarazada que no sólo los gatos la pueden transmitir, sino también el consumo de ciertas carnes crudas o mal cocidas.

Listeria monocytogenes es una bacteria del tipo bacilo gram positivo, ampliamente difundido en la naturaleza, que es capaz de contaminar la más variada gama de alimentos de consumo humano. Se encuentra en el suelo, agua, vegetación, etc., y se puede aislar en muestra de deposiciones de $1-5 \%$ de personas saludables.
Las autoridades de salud han realizado en diversos momentos, análisis de alimentos en busca de esta bacteria. Un estudio sobre 2.145 muestras de productos lácteos y cárnicos, resultaron 77 contaminadas: helados $(3,6 \%)$, queso crema $(0,8 \%)$, productos cárnicos procesados $(3,6 \%)$ y mariscos $(11,6 \%)$. Los serovares identificados fueron $1 / 2 \mathrm{a}$ (25 aislados), 4b (20 aislados), 1/2b (19 aislados), $3 \mathrm{~b}$ (7 aislados), $1 / 2 \mathrm{c}$ (2 aislados) y 4 no tipificables (3). Los serovares $4 b, 1 / 2 a$ y $1 / 2 b$, que son frecuentemente aislados en cepas clínicas, se obtuvieron desde productos lácteos y cárnicos. El año 2000, se analizaron 709 muestras de ensaladas expendidas en supermercados de Santiago. Resultaron positivos un $26 \%$ de ensaladas congeladas y $10,5 \%$ ensaladas frescas. No se aisló Listeria monocytogenes en ensaladas expendidas como un plato preparado frío, listo para consumo. En el 2008, a raíz del brote que ocurrió en la Región Metropolitana, se analizaron 262 muestras de diversos alimentos, en el Instituto de Salud Pública. Se estudiaron 82 muestras de quesos Brie y Camembert, elaborados por una empresa de productos lácteos de la Región Metropolitana, resultando los únicos alimentos que presentaron el mismo patrón genético de las cepas clínicas estudiadas. Otros alimentos, que los pacientes informaron haber consumido, 30 días antes de la aparición de sus síntomas, también resultaron positivos, pero con otro patrón genético. Entre estos, destacan los cárneos de vacuno y de ave crudos, los procesados mediante ahumado, algunas cecinas y embutidos crudos y vegetales congelados.

Estos estudios demuestran la presencia de numerosas variedades de Listeria monocytogenes en los alimentos consumidos en Chile. Esta bacteria significa un gran desafío para la industria de alimentos, pues es capaz de sobrevivir en las más variadas condiciones ambientales, incluido el refrigerador doméstico a $4^{\circ} \mathrm{C}$. Sin embargo, es eliminada por la cocción adecuada y la pasteurización. No obstante, es importante tener en cuenta que estos 
procesos de aseguramiento de la calidad microbiológica de los alimentos, pueden deteriorarse por contaminación cruzada, en una deficiente manipulación posterior.

Las embarazadas tienen un riesgo casi veinte veces superior a la población general de desarrollar la enfermedad, la que se manifiesta generalmente por compromiso de estado general, fiebre, cefalea y mialgias. Puede asociarse a diarrea y vómitos. A diferencia de la manifestación en inmunosuprimidos y recién nacidos, la meningitis en muy infrecuente en embarazadas. En nuestra experiencia, sólo un caso se ha descrito en nuestro país (4). Listeriosis tiene importancia en obstetricia pues cerca de un quinto de las infecciones se asocia a aborto o mortalidad perinatal, y dos tercios de los sobrevivientes pueden desarrollar listeriosis neonatal (sepsis, meningitis).

Listeriosis no ha sido una enfermedad de notificación obligatoria para las autoridades de salud, como tampoco para la vigilancia de los alimentos que se expenden a nivel nacional. Según el DS № 158 del MINSAL, este patógeno está sujeto a vigilancia de laboratorio. Por lo que todo aislamiento realizado en el país, debe confirmarse en el Instituto de Salud Pública (ISP). No obstante, a raíz del brote de listeriosis que afectó a la Región Metropolitana, la SEREMI de Salud de esta región, dispuso, mediante Oficio № 6254 del 09 de septiembre de 2008, la notificación de todo caso confirmado de Listeria monocytogenes, al Subdepartamento de Epidemiología de esa autoridad sanitaria.

En la Región Metropolitana, se aislaban en forma endémica, entre 20 y 26 cepas de Listeria monocytogenes al año, cifra que aumentó casi cinco veces en 2008, notificándose 119 casos confirmados por cultivo ( $40 \%$ en embarazadas y $14 \%$ en recién nacidos). Sólo 42 aislamientos de Listeria monocytógenes se recibieron en el ISP provenientes de Regiones. De todas las cepas estudiadas en el ISP, 78 correspondieron cepas genéticamente relacionadas (cepa epidémica 009).

La percepción de un aumento de casos por parte de los clínicos y el aviso oportuno a las autoridades de salud (SEREMI Metropolitana) permitió que ésta pusiera en marcha una vigilancia activa del brote y su estudio epidemiológico. Se identificaron las principales comunas involucradas de la Región Metropolitana, hasta finalmente llegar a identificar, el alimento responsable de los casos epidémicos.

La epidemiología molecular (responsabilidad del ISP), por otra parte, fue una herramienta fundamental para poder identificar y localizar geográficamente la cepa de Listeria monocytogenes responsable del brote y diferenciarla de los casos endémicos.

Por otro lado, esta investigación aportó una información muy importante para nuestra práctica clínica ya que en el 2008, en la Región Metropolitana hubo un aumento muy importante (tres veces mayor) de aislamientos (54 casos) no relacionados con el brote, en comparación con años precedentes. Esto debe ponernos en alerta en relación a que en períodos endémicos pudiésemos tener un subdiagnóstico importante de una enfermedad grave en embarazadas, que tiene un tratamiento antimicrobiano conocido, barato, accesible en todas las maternidades del país, y que si se inicia precozmente puede cambiar significativamente el pronóstico perinatal. Se ha reportado tratamiento exitoso de listeriosis en el segundo trimestre, permitiendo llevar el embarazo prácticamente a término.

Por ello debemos aprender la lección, y considerar que parte importante de nuestro rol en el control prenatal, es educativo, en una variada gama de temas. Si bien suena poco atractivo en nuestros tiempos, el tema alimentación, debe considerar una parte importante del control prenatal. Recomendaciones tan simples como el adecuado lavado de manos con jabón antes y después de manipular alimentos, leer y seguir las recomendaciones de elaboración y almacenaje de los alimentos, limpiar y sanitizar las superficies donde se prepararon, limpiar los utensilios utilizados para cocinar antes de usarlos para comer, lavar muy bien todas las frutas y verduras, no descongelar los alimentos a temperatura ambiente o en microondas, sino con la cocción en olla (ej, choclo o arvejas congeladas), recalentar en casa la comida preparada en el comercio hasta que salga vapor, limpieza semanal del refrigerador, no consumir carnes, pescados y mariscos crudos o mal cocidos y no consumir quesos blandos no pasteurizados, pueden reducir los casos de listeriosis perinatal.

Del punto de vista del MINSAL, se está estudiando la posibilidad de incorporar la vigilancia de Listeria monocytogenes (así como ya se hace para otros microorganismos) en los alimentos que se comercializan en Chile, normativa que sería también de gran utilidad.

Finalmente, la experiencia vivida durante este brote de listeriosis es buen ejemplo de la utilidad del trabajo multidisciplinario en todas las ramas de salud. La sospecha clínica, el aviso oportuno a las autoridades de salud, el trabajo en terreno de éstas para identificar el alimento involucrado, y de todos los intermediarios de la cadena de comercialización, hasta que éste llega al consumo humano, el apoyo 
de instituciones que pueden parecer tan distantes del trabajo de la salud como el Instituto Geográfico Militar, que confeccionó los mapas, un geógrafo que georeferenció los casos, el Comité de Infecciones Emergentes de la SOCHINF que elaboró los contenidos educativos del díptico, para instruir a los grupos de riesgo, la educación de los médicos gineco-obstetras a sus pacientes en relación a medidas de prevención y a la consulta precoz, la acuciosidad de médicos infectólogos, que no se limitaron a tratar la infección, sino en preguntar a sus pacientes por alimentos consumidos que se pudieran retirar desde sus hogares, para así sospechar de la fuente de origen de la infección e informar inmediatamente, al equipo de Epidemiología de Campo de la SEREMI Metropolitana de Salud.

El descenso en el número de casos se produjo 2 semanas después del retiro de los quesos del mercado (tiempo que correspondería al período de incubación para esta cepa, alrededor 15 días). Ninguno de los casos notificados en la Región Metropolitana, a partir de esa fecha, correspondió al clon epidémico.

Este equipo interdisciplinario, que trabajó coordinadamente, permitió detectar el alimento contaminado, aplicar medidas sanitarias para cortar la cadena de transmisión en pos de grandes objetivos en la salud de nuestro país en general y en la salud materno-perinatal en particular.
Dr Fernando Abarzúa C. Jefe Unidad Medicina Materno-Fetal. Departamento de Obstetricia y Ginecología. Pontificia Universidad Católica de Chile.

Dra. Verónica Solari G. Unidad de Vigilancia de Enfermedades Transmisibles.

Sub Departamento Epidemiología. SEREMI Salud, Región Metropolitana.

\section{BIBLIOGRAFÍA}

1. Wilson $\mathrm{K}$, Keelan J. Learning from Listeria: the autonomy of the Public Health Agency of Canada. CMAJ 2008;179(9):877-9.

2. Noriega LM, Ibáñez $S$, González $P$, et al. Listeria monocytogenes: Report of a rise in pregnant women and literature review. Rev Chilena Infectol 2008;25(5):3429.

3. Cordano AM, Rocourt J. Occurrence of Listeria monocytogenes in food in Chile. Int $\mathrm{J}$ Food Microbiol 2001;70(1-2):175-8.

4. Larraín D, Abarzúa F, de Jourdan F, Merino P, Belmar C, García P. Listeria monocytogenes infection in pregnancy: experience of Pontificia Universidad Católica de Chile University Hospital. Rev Chilena Infectol 2008;25(5):336-41. 